\title{
Improvement of effect of water-in-oil microemulsion as an oral delivery system for fexofenadine: in vitro and in vivo studies
}

This article was published in the following Dove Press journal:

International Journal of Nanomedicine

I I August 201 I

Number of times this article has been viewed

\section{E Gundogdu', \\ I Gonzalez Alvarez ${ }^{3}$ \\ E Karasulu ${ }^{1,2}$ \\ 'Faculty of Pharmacy, Department of Biopharmaceutics and Pharmacokinetics, ${ }^{2}$ Center For Drug Research and Development and Pharmacokinetic Applications, Ege University, Izmir, Turkey; ${ }^{3}$ Faculty of Pharmacy, Department of Engineering, Pharmaceutical Technical Section, Research Group on Drug Absorption, Universidad Miguel Hernández, Alicante, Spain}

Correspondence: Evren Atlihan Gundogdu Department of Biopharmaceutics and Pharmacokinetics, Faculty of Pharmacy, Ege University, Bornova Izmir, Turkey $\mathrm{Tel}+905326966295$

Fax +90 2323885258

Email evren.gundogdu@ege.edu.tr

\begin{abstract}
Fexofenadine (FEX) has high solubility and low permeability (BCS, Class III). In this work, novel FEX loaded water in oil microemulsion (w/o) was designed to improve bioavailability and compared with Fexofen ${ }^{\circledR}$ syrup in in vitro and in vivo studies. In addition, pharmacokinetic parameters in permeability studies were estimated by using WinNonLin software program. w/o microemulsion system was optimized using a pseudoternary phase diagram, composed of span 80/lutrol F 68 (9.5:0.5 w/w), oleic acide, isopropyl alcohol and water as surfactant mixture; oil and cosurfactant was developed for oral drug delivery. w/o microemulsion systems were characterized by phase behavior, particle size, viscosity and solubilization capacity. In vitro studies were studied using Caco- 2 cell monolayer. Pharmacokinetic parameters of w/o microemulsion were investigated in rabbits and compared to Fexofen ${ }^{\circledR}$ syrup. Fexofen ${ }^{\circledR}$ syrup and microemulsion were administered by oral gavage at $6 \mathrm{mg} / \mathrm{kg}$ of the same concentration. The experimental results indicated that microemulsion $(\mathrm{HLB}=5.53)$ formed nanometer sized droplets $(33.29 \pm 1.76)$ and had good physical stability. This microemulsion increased the oral bioavailability of FEX which was highly water-soluble but fairly impermeable. The relative bioavailability of FEX microemulsion was about $376.76 \%$ compared with commercial syrup in rabbits. In vitro experiments were further employed for the enhanced effect of the microemulsion for FEX. These results suggest that novel w/o microemulsion plays an important role in enhancing oral bioavailability of low permeability drugs.
\end{abstract}

Keywords: pharmacokinetic, bioavailability, permeability, oleic acid

\section{Introduction}

Allergic rhinitis is a common disorder associated with a high incidence of morbidity. ${ }^{1}$ Several mediators are involved in the pathophysiology of allergic diseases, so a variety of drugs, including antihistamines, decongestants, intranasal corticosteroids, leukotriene receptor antagonists, topical anticholinergics, mast cell stabilizers, mucolytics, and anti-IgE antibodies are used in the clinical treatment of allergic rhinitis. However, among these mediators, antihistamine remains the principal one, and plays a fundamental role in the genesis of allergic rhinitis. Therefore, antihistamines have been the main class of medications used for the treatment of allergic rhinitis over the past 60 years. . $^{2,3}$

Fexofenadine hydrochloride, the active metabolite of terfenadine, a well known and effective $\mathrm{H}_{1}$ receptor antagonist, is administered by the oral route. It is a nonsedating antihistamine providing rapid, long-acting, and highly selective peripheral $\mathrm{H}_{1}$ receptor antagonist activity. ${ }^{4-6}$ The oral bioavailability of fexofenadine in humans is not established. ${ }^{7}$ However, in other animals, it is known to be as low as $4.2 \%$ (in rats) ${ }^{7}$ and $2.6 \%$ (in horses). ${ }^{8}$ 
In a review of 16 human pharmacokinetic studies, Chen et al reported that the half-life of fexofenadine varies between 3 and 17 hours. ${ }^{9}$ In our study, the half-life of fexofenadine w/o microemulsion was significantly $(P<0.05)$ decreased (by 2.04fold) when compared with a commercial fexofenadine syrup (Fexofen $^{\circledR}$, Sanovel, Istanbul, Turkey) because of differences in clearance rates and distribution volumes for the two formulations. In addition, the enterohepatic circulation is involved in the prolonged plasma elimination half-life of fexofenadine due to increased oral absorption.

The efflux transporter, P glycoprotein, has been reported to transport fexofenadine in in vitro models. Thus, it is considered to be an important determinant of the pharmacokinetics of fexofenadine. ${ }^{10}$ Fexofenadine is a substrate for $\mathrm{P}$ glycoprotein, and concomitant food and coadministration of drugs have significant effects on its oral bioavailability. ${ }^{11}$ In addition, according to the biopharmaceutical classification system, fexofenadine belongs to the Class 3 drugs, which means it has high solubility and low permeability, so an effort to increase the permeability of fexofenadine is needed. ${ }^{12}$

Microemulsions known to enhance bioavailability in the gastrointestinal tract are thermodynamically stable, isotropically clear dispersions of two immiscible liquids, such as oil and water, and are stabilized by an interfacial film of surfactant molecules. ${ }^{13-17}$ Further advantages of using microemulsions as drug delivery systems include better drug solubilization and protection against enzymatic hydrolysis, as well as the potential for enhanced absorption due to a surfactant-induced increment in permeability. In addition, microemulsions represent an interesting and potentially quite powerful alternative carrier system for drug delivery because of their high solubilization capacity, transparency, ease of preparation, and high diffusion and absorption rates when compared with solvents without the surfactant system. ${ }^{18,19}$

In this study, we designed and developed a novel microemulsion formulation to improve the oral absorption of fexofenadine. Absorption of fexofenadine in the intestine was compared with that of Fexofen syrup in vitro and in vivo in rabbits. In particular, Caco-2 cell permeability and the pharmacokinetics of the fexofenadine microemulsion were determined to evaluate the potential of the microemulsion to be an effective oral delivery carrier for drugs with bioavailability problems, like fexofenadine.

\section{Materials and methods Materials}

Fexofenadine was provided by Basel Drug Company (Istanbul, Turkey). Diphenylhydramine was purchased from Sigma
Chemical Co (St Louis, MO). Lutrol F 68 was purchased from BASF (Ludwigshafen, Germany). Span 80, oleic acid, and isopropyl alcohol were obtained from Sigma-Aldrich (St Louis, MO). Cell culture reagents and supplies were obtained from Gibco Invitrogen (Grand Island, NY). Sodium dodecyl sulfate was purchased from Sigma Chemical Co.

\section{Preparation of microemulsion}

\section{Solubility studies}

The solubility of fexofenadine in various oils and surfactants was determined by adding an excess amount of fexofenadine into $1 \mathrm{~mL}$ of each vehicle, followed by shaking (100 rpm) at $25^{\circ} \mathrm{C}$ for 24 hours. The samples were centrifuged at $10000 \mathrm{rpm}$ for 10 minutes to remove excess fexofenadine, and the concentration of fexofenadine in the supernatant was measured by high-performance liquid chromatography (HPLC) after appropriate dilution with isopropyl alcohol.

\section{Construction of pseudoternary phase diagram}

Microemulsion fields formed by dilution and gentle agitation were identified from ternary phase diagrams of systems containing oil-surfactant (S)-cosurfactant (coS). Oleic acid was selected as the oil phase. The effects of surfactants (mixtures of span 80 and lutrol $F 68$ at w/w ratios of 9.5:0.5 with a hydrophilic-lipophilic balance of 5.53) and the cosurfactant (isopropyl alcohol) on the pseudoternary phase diagram were systematically observed at room temperature. Lutrol F 68 were melted at $50^{\circ} \mathrm{C}-60^{\circ} \mathrm{C}$ and blended with span 80 to make the surfactant mixture. Afterwards, the oil phase and the surfactant mixture were mixed. The boundaries of the microemulsion domains were determined for different values of the $\mathrm{S} / \mathrm{coS}(\mathrm{w} / \mathrm{w})$ ratios. The $\mathrm{S} / \mathrm{coS}$ weight ratios were $1: 1,2: 1,3: 1,4: 1$, and 5:1. Distilled water was added dropwise to each clear oil and surfactant mixture with gentle stirring to allow equilibration. Following addition of aliquots in the water phase, the mixture was examined visually for transparency. Based on the results of the pseudoternary phase diagrams, one microemulsion was selected for further experiments (Table 1). Thereafter, the fexofenadine-loaded microemulsion was prepared by adding $6 \mathrm{mg}$ of fexofenadine per $1 \mathrm{~mL}$ of microemulsion with vortexing.

\section{Characterization of microemulsion}

\section{Droplet size determination}

The droplet size, polydispersity, and zeta potential of the microemulsions (with and without fexofenadine) were measured using a zeta sizer $\left(3000 \mathrm{HS}_{\mathrm{A}}\right.$, Malvern Instruments, Worcestershire, UK) with six measurements. 
Table I The solubility of FEX in various vehicles at $25^{\circ} \mathrm{C}$

\begin{tabular}{lc}
\hline Vehicles & FEX $(\mathbf{m g} / \mathbf{m L})$ \\
\hline Water & $1.58 \pm 0.04$ \\
Oil & \\
$\quad$ Oleic acid & $6.15 \pm 0.25$ \\
Surfactants & \\
$\quad$ Lutrol F 68 & $24.95 \pm 0.49$ \\
$\quad$ Span 80 & $12.28 \pm 0.04$ \\
$\quad$ Isopropyl alcohol & $29.55 \pm 0.27$ \\
\hline
\end{tabular}

Abbreviation: FEX, fexofenadine.

\section{Viscosity}

The viscosity of the microemulsions (with and without fexofenadine) was measured at $25^{\circ} \mathrm{C} \pm 0.1^{\circ} \mathrm{C}$ using a Brookfield digital viscometer-III rheometer V 3.3 HB (Middleboro, MA) at $200 \mathrm{rpm}(\mathrm{n}=6)$.

\section{Conductivity measurements}

The effect of the amount of water phase in the microemulsions was monitored quantitatively by measuring electrical conductivity. The water phase was added drop by drop into the mixture of oil phase and, after each drop of water, electrical conductivity was measured using a conductometer WPA CM 35 (Cambridge, UK), at $25^{\circ} \mathrm{C} \pm 0.1^{\circ} \mathrm{C}$. The conductivity of microemulsions with and without fexofenadine was measured $(n=6)$.

\section{$\mathrm{pH}$ measurements}

The $\mathrm{pH}$ values of the samples were measured by a $\mathrm{pH}$ meter (Jenway 3040 Ion Analyze, Combined Glass Electrode, Mettler-Toledo, Greifensee, Switzerland) at $25^{\circ} \mathrm{C} \pm 0.1^{\circ} \mathrm{C}$ $(\mathrm{n}=6)$.

\section{HPLC analysis of fexofenadine}

HPLC was used for the loading content and permeability studies of fexofenadine. Samples were appropriately diluted with isopropyl alcohol to $20 \mu \mathrm{L}$ and injected directly into the HPLC system without further treatment. The HPLC system was equipped with a Waters 2487 . A reverse phase $\mathrm{C}_{18}$ column $(250 \mathrm{~mm} \times 4 \mathrm{~mm}, 5 \mu \mathrm{m}) \mathrm{LiChroCART}^{\circledR}$ (Merck, Darmstadt, Germany) was used at room temperature. The excitation and emission wavelengths of the fluorescence detector were set as $220 \mathrm{~nm}$ and $290 \mathrm{~nm}$, respectively. A mixture of acetonitrile and $0.05 \mathrm{M} \mathrm{pH} 3.2$ potassium dihydrogen phosphate buffer solutions $(60: 40, \mathrm{v} / \mathrm{v})$ was used as the mobile phase at a flow rate of $1.0 \mathrm{~mL} / \mathrm{min}$.

\section{Content of fexofenadine}

Petroleum ether $2.5 \mathrm{~mL}$ was added to $200 \mathrm{~mL}$ of microemulsion containing fexofenadine and mixed for three minutes at $1000 \mathrm{rpm}$, followed by addition of $2.5 \mathrm{~mL} 0.05 \mathrm{M} \mathrm{pH} 3.2$ potassium dihydrogen phosphate buffer solution. The mixture was vortexed and centrifuged at $3000 \mathrm{rpm}$ for 15 minutes. Finally, the upper liquid phase was constituted with $2.5 \mathrm{~mL}$ of mobile phase, and $20 \mu \mathrm{L}$ was injected into the HPLC system $(n=6)$.

\section{Stability test}

To evaluate the stability of the optimized formulation of fexofenadine, the microemulsion was put into sealed glass vials, which were stored at $25^{\circ} \mathrm{C}$ and $40^{\circ} \mathrm{C}$ for 6 months. The clarity, concentration of fexofenadine, and droplet size were thereafter investigated at predetermined intervals $(n=6)$.

\section{Permeability studies in Caco-2 cell monolayer \\ Cell cultures}

The colonic adenocarcinoma cell line, Caco-2, was obtained from the American Type Culture Collection, and cultured in Dulbecco's Modified Eagle Medium. The cell monolayers were prepared by seeding $4 \times 10^{5}$ cells/well on a 6 -well Transwell ${ }^{\circledR}$ insert filter. Cell cultures were maintained at $37^{\circ} \mathrm{C}$ under $90 \%$ humidity and $5 \% \mathrm{CO}_{2}$. Monolayers were used 19-22 days after seeding. The integrity of each cell monolayer was checked by measuring its transepithelial electrical resistance (TEER) with an epithelial Volt-Ohm meter (EVOM, World Precision Instrument, Sarasota, FL) before and after the experiments $(n=6)$.

\section{Permeability of fexofenadine from microemulsion versus syrup}

The in vitro permeability study was developed in Caco- 2 cell monolayers grown in Transwell inserts with collagen-coated polycarbonate membranes having a pore size of $0.4 \mu \mathrm{m}$ and a surface area of $4.7 \mathrm{~cm}^{2}$. The cells were maintained at $37^{\circ} \mathrm{C}$ in the atmospheric conditions described earlier. The medium was replaced every second day for 3 weeks. For the experiment with Caco- 2 cell monolayers, w/o microemulsion (fexofenadine $6 \mathrm{mg} / \mathrm{mL}$ ) and commercial syrup (6 mg/ $\mathrm{mL}$ ) formulations were diluted up to $95 \%$ (v/v) with Hank's Buffered Salt Solution (HBSS).

The permeability studies were performed in both directions, ie, from apical to basolateral and basolateral to apical. After washing the Caco-2 cell monolayer twice with prewarmed HBSS medium ( $\mathrm{pH} 7.4$ ), the fexofenadine microemulsion was diluted with HBSS $(95 \% \mathrm{v} / \mathrm{v})$. The transport experiments were done by adding the fexofenadine microemulsion diluted with HBSS to either the apical 
(2.2 $\mathrm{mL})$ or basolateral side $(3.2 \mathrm{~mL})$, while the receiving chamber contained the corresponding volume of transport medium. After shaking at $50 \mathrm{rpm}$ for 2 hours at $37^{\circ} \mathrm{C}$ in a water bath, samples were collected from both sides of the Caco- 2 cell monolayer and immediately stored below $-20^{\circ} \mathrm{C}$ for subsequent HPLC analysis. The same procedure was used for the syrup formulation.

Apparent permeability values $\left(P_{\text {app }}\right)$ for each side were calculated according to the following equation:

$$
P_{\mathrm{app}}=\frac{\mathrm{dQ}}{\mathrm{dt}} \frac{1}{\mathrm{ACo} 60}
$$

where $P_{\text {app }}$ is the apparent permeability $(\mathrm{cm} / \mathrm{sec}), \mathrm{dQ} / \mathrm{dt}$ is the permeation rate, $\mathrm{A}$ is the diffusion area of monolayers $\left(\mathrm{cm}^{2}\right)$, and $\mathrm{Co}$ is the initial concentration of drug in the donor compartment. ${ }^{1}$

\section{Pharmacokinetic studies in rabbits}

\section{Study design}

Two groups of rabbits (weight $1.8-2.5 \mathrm{~kg}$, provided by the Central Animal Laboratory of Ege University) were used to perform the in vivo pharmacokinetic study. Six rabbits were allocated to each group. All rabbits were maintained in a light-controlled room at a temperature of $25^{\circ} \mathrm{C} \pm 0.5^{\circ} \mathrm{C}$. The experimental protocols were approved by the Animal Care and Use Committee of the College of Pharmacy, Ege University. Before the experiment, the rabbits were fasted overnight for 12 hours with free access to water, and remained conscious throughout the experiment. For the oral administration, the fexofenadine syrup and w/o microemulsion formulations were administered at the same doses by oral gavage (6 mg/kg body weight). Blood samples $(2 \mathrm{~mL})$ were withdrawn from the ear vein at predetermined time intervals (hours $0,1,2,3,4,5,6,7$, and 8 ), and $75 \mu \mathrm{L} / \mathrm{mL}$ of heparin solution was used to maintain patency of the cannula between sampling times. Plasma samples were obtained by immediately centrifuging the blood samples at 10,000 rpm for 10 minutes, after which $500 \mu \mathrm{L}$ of each plasma sample was stored at $-20^{\circ} \mathrm{C}$ until analyzed by HPLC.

\section{Plasma analysis}

The fexofenadine concentration in the plasma samples was analyzed by HPLC. ${ }^{20}$ Briefly, plasma samples $(500 \mu \mathrm{L})$ were mixed with $2 \mu \mathrm{g} / \mathrm{mL}$ of internal standard (DFN) and $1500 \mu \mathrm{L}$ of methanol. The mixture was vortexed for 10 minutes and centrifuged at $4000 \mathrm{rpm}$ for 5 minutes at $5^{\circ} \mathrm{C} \pm 0.5^{\circ} \mathrm{C}$, and the supernatant was evaporated to dryness under nitrogen at $40^{\circ} \mathrm{C}$. The residue was reconstituted with $200 \mu \mathrm{L}$ of mobile phase and injected into the HPLC system. Chromatography was performed using $3 \mu \mathrm{m} \mathrm{C}_{18}$ columns $(100 \mathrm{~mm} \times 3 \mathrm{~mm}$, Phenomenex, Torrance, CA) at a flow rate of $0.8 \mathrm{~mL} / \mathrm{min}$ with acetonitrile $0.02 \mathrm{M}$ potassium dihydrogen phosphate buffer solution mixture $(25: 75, \mathrm{v} / \mathrm{v})$ as the mobile phase at room temperature. A calibration curve was constructed in the range of $0.5-30 \mu \mathrm{g} / \mathrm{mL}$. The mean correlation coefficient $\left(r^{2}\right)$ for the calibration curve was at least 0.999 .

\section{Pharmacokinetic analysis}

The pharmacokinetic parameters for fexofenadine after administration of the microemulsion and syrup were calculated for each rabbit using the WinNonlin ${ }^{\circledR}$ program (Version 3.1, Pharsight Co, Mountainview, CA). Noncompartmental analysis was used to calculate the peak plasma concentration, time taken to reach peak concentration, and the area under the curve (AUC). The relative bioavailability of the oral drug delivery system was calculated as follows:

$$
\text { Relative bioavailability }=\frac{(A U C) \text { microemulsion }}{(A U C) \text { syrup }} \times 100
$$

\section{Statistical analysis}

A two-tailed unpaired Student's $t$-test was performed, with $P<0.05$ considered to be statistically significant.

\section{Results Solubility studies}

The solubility of fexofenadine in the various vehicles is shown in Table 1. Isopropyl alcohol was selected as a cosurfactant for the study because it has the highest solubility for fexofenadine and has been reported to have a favorable enhancing effect on the oral bioavailability of fexofenadine. ${ }^{9}$ Oleic acid was chosen as the oily phase for its good drug solubility (Table 1). Span 80 and lutrol F 68 were selected as surfactants due to their ability to augment drug solubilization. ${ }^{7}$

\section{Construction of pseudoternary phase diagrams}

Investigation of the phase behavior of these systems demonstrated that our approach was suitable for determining the water phase, oil phase, surfactant concentration, and cosurfactant concentration at which the transparent phase microemulsion system was formed. ${ }^{21}$ The construction of a phase diagram makes it easy to identify the concentration range of components in the microemulsions. Figure 1 shows the 

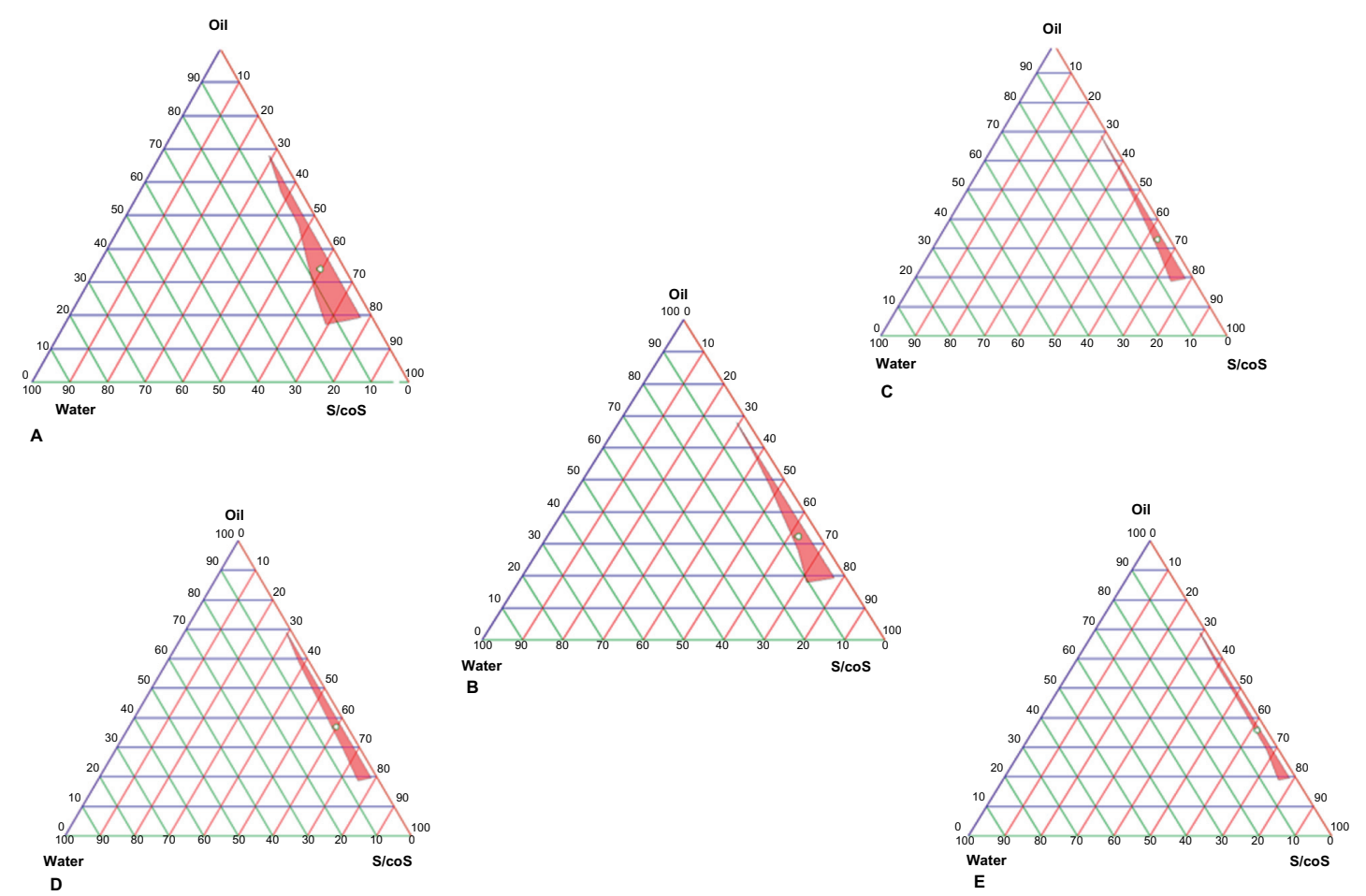

Figure I Pseudoternary phase diagrams of microemulsion system. (A) I:I S/coS ratio, (B) 2:I S/coS ratio, (C) 3:I S/coS ratio, (D) 4:I S/coS ratio, (E) 5:I S/coS ratio.

phase diagrams constructed to determine the optimum $\mathrm{S} / \mathrm{coS}$ concentration ratio for the formulation of w/o microemulsion consisting of span 80 , lutrol F 68, oleic acid, isopropyl alcohol, and water. The $\mathrm{S} / \mathrm{coS}$ and surfactant mixture (span 80/lutrol F 68) ratios were found to be $1: 1$ and 9.5:0.5 for the optimized microemulsion. As shown in Figure 1A, the area of $\mathrm{w} / \mathrm{o}$ microemulsion becomes enlarged and is highest at a $\mathrm{S} / \mathrm{coS}$ ratio of 1:1. The exact composition according to oil, surfactant, cosurfactant, and aqueous phases is shown in Table 2.

\section{Characterization of microemulsion}

The physicochemical characteristics of the microemulsions are shown in Table 3. Particle size analysis showed that the mean droplet size for the microemulsions with and without fexofenadine was below $100 \mathrm{~nm}$. Microemulsions without fexofenadine were transparent colloidal dispersions with an average diameter of $39.05 \mathrm{~nm}$ and a polydispersity index of 0.044 . When fexofenadine was loaded into the microemulsion system, the microemulsion did not change in transparency or polydispersity index value, but the mean droplet size decreased from $39.05 \mathrm{~nm}$ to $33.29 \mathrm{~nm}$. A possible

Table 2 The contents of optimized microemulsion formulation

\begin{tabular}{llllll}
\hline Formulation & Oil (\%) & $\mathbf{S}_{1}(\%)$ & $\mathbf{S}_{2}(\%)$ & $\operatorname{coS}(\%)$ & Water (\%) \\
\hline Microemulsion & 34.05 & $\mathrm{I} .49$ & 28.31 & 29.79 & 6.36 \\
\hline
\end{tabular}

Notes: S, Lutrol F 68, S : Span 80, coS: Isopropyl alcohol. reason for this might be that the contents of the microemulsion and fexofenadine affect each other. When the fexofenadine molecule is dissolved and dispersed into the emulsifying membrane layer (composed of surfactant and cosurfactant) and oil phase, the chemical groups in the fexofenadine molecule can react with the other groups in the surfactant, cosurfactant, and oil phase, producing hydrogen bonds. This could be due to the decreased surface tension created by the presence of surfactant and cosurfactant. ${ }^{22}$ In addition, the zeta potential was measured. When fexofenadine was loaded to the microemulsion system, the zeta potential of the microemulsion increased from $1.95 \mathrm{mV}$ to $2 \mathrm{mV}$. This increment was not statistically significant $(P<0.05)$. It is clear from the physicochemical data (Table 3 ) that microemulsions with and without fexofenadine had similar values for viscosity, conductivity, and $\mathrm{pH}(P>0.05)$.

\section{Fexofenadine content}

Table 3 shows that the fexofenadine content in the microemulsion system was approximately $5.98 \mathrm{mg} / \mathrm{mL}$. Loading of fexofenadine into the w/o microemulsion system was obtained, with an encapsulation efficiency of $99.67 \%$.

\section{Stability test}

After storage at $25^{\circ} \mathrm{C}$ and $40^{\circ} \mathrm{C}$ for 6 months, the optimized fexofenadine microemulsion remained clear and transparent 
Table 3 Characterization of microemulsion

\begin{tabular}{|c|c|c|c|c|c|c|}
\hline Samples & $\begin{array}{l}\text { Electrical conductivity } \\
\left(\mu \mathrm{s} \mathrm{cm}^{-1}\right)\end{array}$ & $\begin{array}{l}\text { Viscosity } \eta \\
\text { (cps) }\end{array}$ & $\begin{array}{l}\text { Droplet size } \\
(\mathrm{nm})\end{array}$ & Polydispersity & $\begin{array}{l}\text { Zeta potential } \\
(\mathrm{mV})\end{array}$ & $\begin{array}{l}\text { Content of FEX } \\
\mathrm{mg} / \mathrm{mL}\end{array}$ \\
\hline$A$ & $\mathrm{I} \pm 0.03$ & $104.7 \pm 0.15$ & $39.05 \pm 0.87$ & $0.044 \pm 0.01$ & $-1.95 \pm 0.12$ & - \\
\hline B & $\mathrm{I} . \mathrm{I} \pm 0.02$ & $103.8 \pm 0.25$ & $33.29 \pm 1.76$ & $0.044 \pm 0.02$ & $-2.13 \pm 0.21$ & $5.98 \pm 0.17$ \\
\hline
\end{tabular}

Notes: A: Microemulsion without FEX, B: Microemulsion with FEX.

Abbreviation: FEX, fexofenadine.

without any phase separation. Table 4 shows that the fexofenadine concentration and droplet size in the microemulsion was not changed significantly, suggesting that the fexofenadine-loaded microemulsion was stable under the above conditions.

\section{Permeability of fexofenadine in Caco-2 cell monolayer}

Figure 2 shows the permeability profiles for fexofenadine from the w/o microemulsion and from the commercial syrup across the Caco- 2 cell monolayers. The permeability studies were performed at $37^{\circ} \mathrm{C}$. The results indicate that permeability of fexofenadine from the w/o microemulsion was greater than that of the syrup formulation. The bidirectional $P_{\text {app }}$ values for both formulations are summarized in Table 5.

Generally, substances with an apparent permeability coefficient $\left(P_{\text {app }}\right)<1 \times 10^{-6} \mathrm{~cm} / \mathrm{sec}$ are classified as low permeability substances, and those with an apparent permeability coefficient $>1 \times 10^{-5} \mathrm{~cm} / \mathrm{sec}$ are classifed as high permeability substances. ${ }^{7}$ The microemulsion and commercial syrup formulations had high permeability for both directions. $P_{\text {app B toA }}$ (permeability from basolateral to apical direction) was higher than $P_{\text {appA to B }}$ (permeability from apical to basolateral direction)

Table 4 Stablity of optimum microemulsion containing FEX (A) and (B)

\begin{tabular}{|c|c|c|c|c|}
\hline \multirow{2}{*}{$\begin{array}{l}\text { Temperature/ } \\
\text { month }\end{array}$} & \multicolumn{2}{|l|}{$25^{\circ} \mathrm{C}$} & \multicolumn{2}{|l|}{$40^{\circ} \mathrm{C}$} \\
\hline & $\begin{array}{l}\text { Droplet } \\
\text { size } \\
(\mathrm{nm})\end{array}$ & $\begin{array}{l}\text { Content } \\
\text { of FEX } \\
(\mathrm{mg} / \mathrm{mL})\end{array}$ & $\begin{array}{l}\text { Droplet } \\
\text { size } \\
(\mathrm{nm})\end{array}$ & $\begin{array}{l}\text { Content } \\
\text { of FEX } \\
(\mathrm{mg} / \mathrm{mL})\end{array}$ \\
\hline \multicolumn{5}{|l|}{ (A) } \\
\hline 0 & $33.29 \pm 0.95$ & $5.98 \pm 0.17$ & $33.29 \pm 0.95$ & $5.98 \pm 0.17$ \\
\hline 3 & $33.72 \pm 0.61$ & $5.89 \pm 0.24$ & $34.01 \pm 0.55$ & $6.11 \pm 0.12$ \\
\hline \multirow[t]{3}{*}{6} & $33.34 \pm 0.44$ & $6.01 \pm 0.16$ & $34.72 \pm 0.85$ & $6.09 \pm 0.35$ \\
\hline & \multicolumn{2}{|l|}{$25^{\circ} \mathrm{C}$} & \multicolumn{2}{|l|}{$40^{\circ} \mathrm{C}$} \\
\hline & \multicolumn{2}{|c|}{ Zeta potiential $(\mathrm{mV})$} & \multicolumn{2}{|c|}{ Zeta potiential $(\mathrm{mV})$} \\
\hline \multicolumn{5}{|l|}{ (B) } \\
\hline 0 & \multicolumn{2}{|l|}{$2.13 \pm 0.21$} & \multicolumn{2}{|l|}{$2.13 \pm 0.21$} \\
\hline 3 & \multicolumn{2}{|l|}{$2.1 \pm 0.14$} & \multicolumn{2}{|l|}{$2.11 \pm 0.2$} \\
\hline 6 & \multicolumn{2}{|l|}{$2.01 \pm 0.09$} & \multicolumn{2}{|l|}{$2.14 \pm 0.15$} \\
\hline
\end{tabular}

Abbreviation: FEX, fexofenadine. for both formulations, consistent with the contribution of a secretion transporter, and fexofenadine has been demonstrated to be a $P$ glycoprotein substrate. ${ }^{8}$ When the fexofenadine microemulsion was applied to the Caco-2 cell, the $P_{\text {app A to B }}$ was increased $\left(2.55 \times 10^{-5} \pm 0.05 \mathrm{~cm} / \mathrm{sec}\right)$ compared with the $P_{\text {app A to B }}$ of the syrup $\left(1.97 \times 10^{-5} \pm 1.23 \mathrm{~cm} / \mathrm{sec}\right)$, and the $P_{\text {app B to A }}$ was increased $\left(2.61 \times 10^{-5} \pm 1.77 \mathrm{~cm} / \mathrm{sec}\right)$ compared with the $P_{\text {app BtoA }}$ of the syrup $\left(2.39 \times 10^{-5} \pm 1.33 \mathrm{~cm} / \mathrm{sec}\right)$. These findings suggest that fexofenadine in the microemulsion has higher permeability than when in the commercial syrup form. This also indicates that the microemulsion is an enhancer of fexofenadine permeability.

\section{Effect of fexofenadine on TEER across Caco- 2 cell monolayer}

TEER values across Caco- 2 cells have been used as indicators of tight junction integrity in cell monolayers. Therefore, the effects of both formulations on the ability to modulate tight junctions could be monitored using this indicator. Experiments performed with the commercial syrup showed a change in TEER of $<20 \%$ for 2 hours in both directions (apical to basolateral and basolateral to apical). However, experiments with the microemulsion showed a reduction in TEER over the 2 hours, with TEER being $33.7 \%$ and $41.1 \%$ of control values at 2 hours in the apical to basolateral and basolateral to apical directions, respectively (Table 6). Changes in TEER after treatment with the microemulsion were statistically significant compared with the commercial syrup $(P<0.05)$. In general, the microemulsion-induced decrease in TEER was correlated with an increase in permeability of fexofenadine.

\section{Estimation of fexofenadine transport parameters}

Fexofenadine permeability values for the microemulsion were higher than for the syrup in the basolateral to apical and apical to basolateral directions. This is consistent with the presence of surfactant and cosurfactant as permeability enhancers. The following model equations, including the passive diffusion component and the Michelis-Menten component, were fitted to the dataset for apical to basolateral 


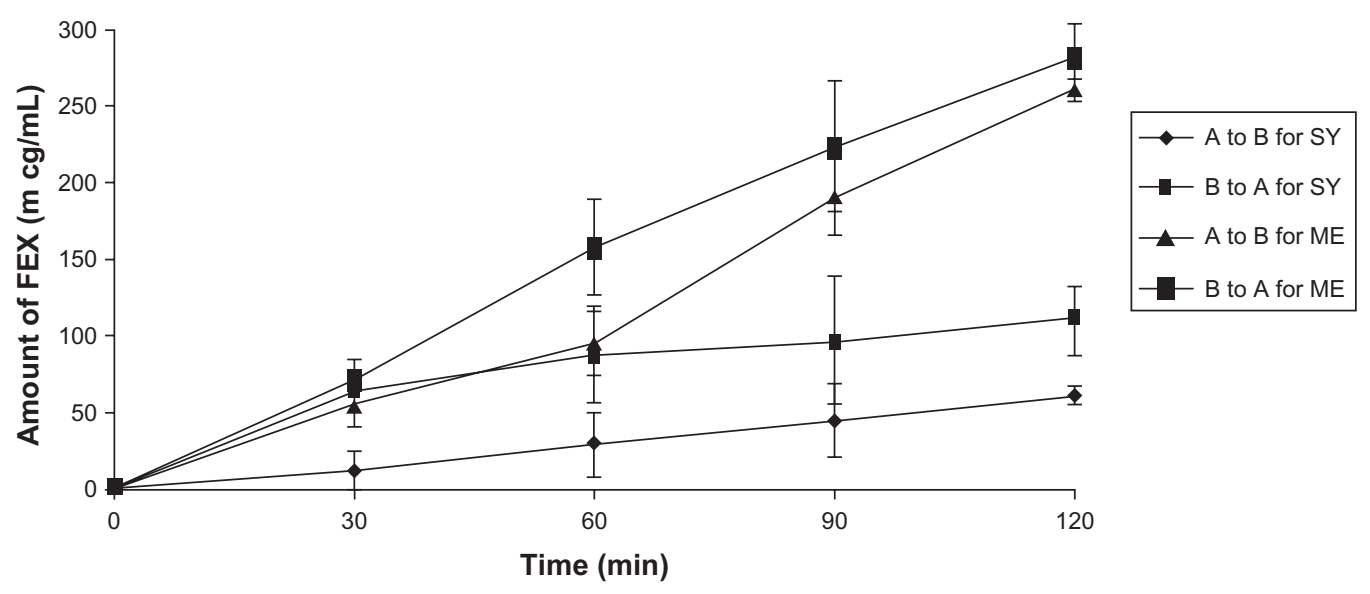

Figure 2 The amount of FEX permeability across Caco-2 cell $(n=6 \pm S D)$.

Notes: A to B for SY = The amount of FEX from apical to basolateral direction of syrup, B to A for SY = The amount of FEX from basolateral to apical direction of syrup, $A$ to $B$ for $M E=$ The amount of FEX from apical to basolateral direction of microemulsion, $B$ to $A$ for ME $=$ The amount of FEX from basolateral to apical direction of microemulsion.

Abbreviations: A, apical; B, basolateral; FEX, fexofenadine; ME, microemulsion; SD, standard deviation; SY, syrup.

and basolateral to apical permeabilities in order to estimate the passive component and $\mathrm{Vm}$ and $\mathrm{Km}$.

$$
\begin{aligned}
& P_{\text {eff }}=P_{\text {dif }}-\frac{\mathrm{Vm}}{\mathrm{Km}+\mathrm{C}} \\
& P_{\text {eff }}=P_{\text {dif }}+\frac{\mathrm{Vm}}{\mathrm{Km}+\mathrm{C}}
\end{aligned}
$$

where $P_{\text {eff }}$ is the experimental permeability value, $P_{\text {dif }}$ is the passive diffusion component, and $\mathrm{Vm}$ and $\mathrm{Km}$ are the Michelis-Menten parameters. A second model was explored with the following equations:

$$
\begin{gathered}
P_{\text {eff }}=P_{\text {dif }}-\frac{\mathrm{Vm}}{\mathrm{Km}+\mathrm{C}} \\
P_{\text {eff }}=P_{\text {dif }}+\frac{\mathrm{Vm}}{A^{*} \mathrm{Km}+\mathrm{C}}
\end{gathered}
$$

in which $A$ is a correction factor included to take into account the fact that the binding site of the secretion carrier is located inside the cells so it actually "sees" a different formulation than the donor chamber one. This factor helps to explain why permeability versus concentration is not symmetrical around $P_{\text {dif }}$ in both directions. The change in apparent permeability is more evident in the basal to apical direction because the basolateral membrane has lower resistance, and when the drug is applied in the basolateral chamber, the extracellular and intracellular concentrations are more similar than when the drug is placed in the apical chamber. ${ }^{23}$ The parameters obtained with both kinetic models for the commercial syrup and microemulsion are summarized in Table 7. In order to compare the two models, the sum of squared residuals and Akaike information criterion values were tabulated.

The residual variances from both fits (sum of squared/ degrees of freedom) were compared using the Snedecor's $F$ test and an alpha value of 0.05 with the following equation:

$$
F_{\text {calc }}=\frac{\left(\mathrm{SSR}_{1}-\mathrm{SSR}_{2}\right) /\left(\mathrm{df}_{1}-\mathrm{df}_{2}\right)}{\mathrm{SSR}_{2} / \mathrm{df}_{2}}
$$

where $\mathrm{SSR}_{1}$ is the sum of the squared residual of the simplest models and $\mathrm{SSR}_{2}$ is the sum of the squared residuals of the more complex model, and df are the degrees of freedom of the fit (number of data points minus number of parameter estimated). The calculated $F$ was higher than the tabulated $F$, indicating statistical significance of the more complex model, so the inclusion of parameter $A$ improves the fit to the experimental data.

\section{Pharmacokinetic studies in rabbits}

Figure 3 shows the plasma concentration-time profiles of fexofenadine after administration of the w/o microemulsion

Table 5 The permeability value of FEX with different formulations $(n=6 \pm S D)$

\begin{tabular}{llll}
\hline Formulation & $\boldsymbol{P}_{\text {app A to B }} 10^{-5}(\mathrm{~cm} / \mathrm{s})$ & $\boldsymbol{P}_{\text {app B to A }} 10^{-5}(\mathrm{~cm} / \mathrm{s})$ & $\boldsymbol{P}_{\text {app B to A }} / \boldsymbol{P}_{\text {app A to B }}$ ratio \\
\hline SY & $1.97 \pm 0.23$ & $2.39 \pm 0.77$ & 1.21 \\
ME & $2.55 \pm 0.05$ & $2.61 \pm 1.33$ & 1.02 \\
\hline
\end{tabular}

Abbreviations: A, apical; B, basolateral; FEX, fexofenadine; ME, microemulsion; SD, standard deviation; SY, syrup. 
Table 6 The \% TEER change of experiments across Caco-2 cell for both directions with $\pm \mathrm{SD}(\mathrm{A} \rightarrow \mathrm{B}$ : Apical to basolateral direction, $B \rightarrow A$ basolateral to apical direction)

\begin{tabular}{lllll}
\hline \% TEER Change & & & \\
\hline SY & & & ME & \\
\cline { 1 - 2 } $\mathbf{A} \rightarrow \mathbf{B}$ & B $\rightarrow$ A & & A $\rightarrow$ B & B $\rightarrow$ A \\
\hline$-\mid 2.8 \pm 0.23$ & $-14.7 \pm 0.88$ & & $-33.7 \pm 2.76$ & $-4|| \pm 3.2 \mid$.
\end{tabular}

Abbreviations: A, apical; B, basolateral; $M E$, microemulsion; SD, standard deviation; SY, syrup; TEER, transepithelial electrical resistance.

and the syrup to rabbits, each at a dose of $6 \mathrm{mg} / \mathrm{kg}$ body weight $(n=6)$. Table 8 shows the pharmacokinetic parameters for fexofenadine that were evaluated by the noncompartmental method using the oral WinNonLin program. In this study, oral administration of w/o microemulsion in lower doses gave significantly higher peak plasma concentrations and AUC values compared with the syrup. The mean peak fexofenadine concentration in the group treated with the syrup was $1.97 \mu \mathrm{g} / \mathrm{m}$; a higher mean peak value of $18.63 \mu \mathrm{g} / \mathrm{mL}$ was obtained in the group treated with the microemulsion. This difference was statistically significant $(P<0.05)$. In the case of oral administration, the mean residence time and time to peak plasma concentrations obtained from the w/o microemulsion were significantly prolonged $(P<0.05)$ when compared with those for the syrup.

There have been many previous attempts at estimating the absolute oral bioavailability of fexofenadine, with values ranging widely from $10 \%$ to $90 \% .{ }^{24}$ For example, Chen found that the absolute bioavailability of fexofenadine was $35 \% .{ }^{9}$ In this study, the relative bioavailability related to the $\mathrm{AUC}_{0 \rightarrow 8}$ of fexofenadine was found to be $376.76 \%$ in w/o microemulsion compared with the syrup. This may be because the microemulsion allows the drug to be retained

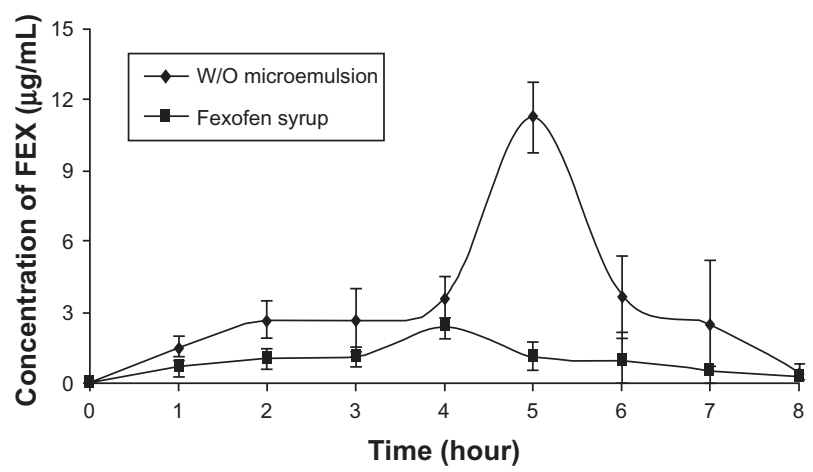

Figure 3 Comparison of the plasma concentration values obtained after administration of FEX loaded microemulsion and Fexofen ${ }^{\circledR}$ syrup.

Abbreviation: FEX, fexofenadine; w/o, water in oil.

long enough in the gastrointestinal system to be well permeated in the gastrointestinal mucosa. According to the relative bioavailability value, the amount of fexofenadine in the microemulsion can be reduced, enabling a lower-dose formulation. Furthermore, a higher relative bioavailability, delayed mean residence time, and extended time to peak concentration with the fexofenadine microemulsion suggested that this microemulsion could have extendedrelease characteristics, and might be useful for extendedrelease oral formulations of fexofenadine.

\section{Discussion}

The minimum absolute oral bioavailability of fexofenadine in this study was $10 \%-15 \%$, based on the amount of unchanged drug appearing in the urine. ${ }^{9}$ Extrapolation from animal data is unreliable, with oral bioavailability being $2 \%-4 \%$ in rodent ${ }^{25}$ and only marginally higher at $6.6 \%$ in monkeys. ${ }^{26}$ An estimate of $30 \%$ bioavailability in man has been made

Table 7 Parameters of the fit of the models with passive component an Michaelis-Menten component and goodness of fit indexes

\begin{tabular}{|c|c|c|c|c|c|c|c|}
\hline SY & Value & SD & CV\% & ME & Value & SD & CV\% \\
\hline$P_{\text {dif }}(\mathrm{cm} / \mathrm{s})$ & $2.24 \mathrm{E}-05$ & 8.79E-08 & 3.92 & Pdif $(\mathrm{cm} / \mathrm{s})$ & 3.5। E-05 & $6.55 \mathrm{E}-08$ & 2.13 \\
\hline $\mathrm{Km}(\mu \mathrm{M})$ & 681.5 & 260.56 & 38.23 & $\mathrm{Km}(\mu \mathrm{M})$ & 89345 & 310.42 & 36.17 \\
\hline $\mathrm{Vm}\left(\mathrm{nMol} \cdot \mathrm{cm}^{-2} \cdot \mathrm{s}^{-1}\right)$ & 0.0132 & 0.000405 & 30.69 & $\mathrm{Vm}\left(\mathrm{nMol} \cdot \mathrm{cm}^{-2} \cdot \mathrm{s}^{-1}\right)$ & 0.0452 & 0.001105 & 23.46 \\
\hline SSR & I.30E-II & & & SSR & $1.8 \mathrm{E}-1 \mathrm{I}$ & & \\
\hline $\mathrm{AIC}$ & -1046 & & & AIC & -1087 & & \\
\hline Parameter & Value & SD & CV\% & Parameter & Value & SD & CV\% \\
\hline$P_{\text {dif }}(\mathrm{cm} / \mathrm{s})$ & $2.57 \mathrm{E}-05$ & I.23E-07 & 4.77 & Pdif $(\mathrm{cm} / \mathrm{s})$ & $3.42 \mathrm{E}-05$ & $0.92 \mathrm{E}-07$ & 5.22 \\
\hline $\mathrm{Km}(\mu \mathrm{M})$ & 513.91 & 160.38 & 31.21 & $\mathrm{Km}(\mu \mathrm{M})$ & 634.76 & 145.87 & 25.29 \\
\hline $\operatorname{Vm}\left(\mathrm{nMol} \cdot \mathrm{cm}^{-2} \cdot \mathrm{s}^{-1}\right)$ & 0.0147 & 0.000391 & 26.48 & $\operatorname{Vm}\left(\mathrm{nMol} \cdot \mathrm{cm}^{-2} \cdot \mathrm{s}^{-1}\right)$ & 0.0521 & 0.000198 & 27.81 \\
\hline A & 2.79 & 0.86 & 30.82 & A & 3.11 & 0.56 & 25.31 \\
\hline SSR & $9.10 \mathrm{E}-12$ & & & SSR & $10.08 \mathrm{E}-12$ & & \\
\hline $\mathrm{AIC}$ & -1059 & & & AIC & -1098 & & \\
\hline
\end{tabular}

Abbreviations: A, apical; B, basolateral; AIC, Akaike's information criteria; CV, coefficient of variability; ME, microemulsion; Pdif, passive diffusion component; SD, standard deviation; SSR, sum of squared residuals; SY, syrup.

Note: $\mathrm{Vm}$ and $\mathrm{Km}$ are the Michaelis-Menten parameters. 


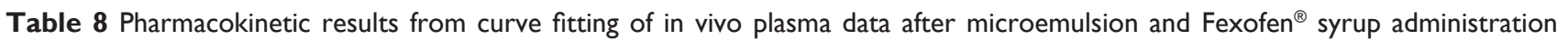
$(n=6)$ with SD

\begin{tabular}{lccccc}
\hline Samples & $\mathbf{T}_{\max }$ (hour) & $\mathbf{t}_{1 / 2}$ (hour) & $\mathbf{C}_{\max }(\mu \mathrm{g} / \mathrm{mL})$ & AUC $_{(0-8)}$ (hour) $(\mu \mathrm{g} / \mathbf{m L})$ & $\mathbf{M R T}(\mathrm{hour})$ \\
\hline ME & $5 \pm 0.01$ & $0.71 \pm 0.31$ & $18.63 \pm 5.74$ & $26.11 \pm 1.1$ & $4.69 \pm 0.19$ \\
SY & $4.67 \pm 0.81$ & $1.45 \pm 0.62$ & $1.97 \pm 0.95$ & $6.93 \pm 1.49$ & $4.01 \pm 0.26$ \\
\hline
\end{tabular}

Abbreviations: AUT, area under the curve; ME, microemulsion with fexofenadine; MRT, mean resistance time; SD, standard deviation; SY, Fexofen ${ }^{\circledR}$ syrup.

based on two observations, ${ }^{9}$ one being the $10 \%$ recovery in urine after oral fexofenadine and the other the finding that fexofenadine is formed by the metabolism of orally administered terfenadine (which is rapidly and extensively metabolized), and is assumed to occur systemically.

To improve its oral bioavailability, some absorption enhancers can be used to improve the oral absorption of fexofenadine, such as chitosan, sodium deoxycholate, and sodium dodecyl sulfate. ${ }^{27}$ However, these enhancers can lead to irritation of the intestinal tract, resulting in substantial damage to the intestinal mucosa. ${ }^{28}$ Thus, it is hoped that a suitable pharmaceutical formulation of fexofenadine can be developed to improve intestinal absorption without damaging the intestinal tissue. Our w/o microemulsion system with surfactant and cosurfactant has the ability to form microemulsions, with good biological acceptance, which is the main reason for their use. ${ }^{29}$ Water-soluble drugs are solubilized in w/o microemulsion and incorporated mainly in the water-phase core and therefore are released rather slowly. ${ }^{30}$ In this study, the viscosity, refractive index, particle size, zeta potential, and electric conductivity of the microemulsion were investigated. The results demonstrated successful formation of a w/o microemulsion containing oil, surfactant/cosurfactant, and an aqueous phase. The optimal w/o microemulsion, consisting of oleic acid, lutrol F-68, span 80, and isopropyl alcohol, is a promising formulation for increasing absorption of fexofenadine by the oral route and could also increase the oral bioavailability of other drugs with low permeability. There are several barriers to the oral delivery of such drugs, including luminal enzymatic hydrolysis, low solubility, and low membrane permeability. ${ }^{31,32}$ Fexofenadine has good stability against enzymatic hydrolysis and at different $\mathrm{pH}$ values. ${ }^{33}$ For fexofenadine, low membrane permeability is the main barrier to its oral absorption. However, because of its good solubility, significantly improved absorption and bioavailability was found for fexofenadine after oral administration of the w/o microemulsion than with the commercial syrup formulation in rabbits.

\section{Conclusion}

A novel fexofenadine-loaded microemulsion was designed to improve the oral absorption of fexofenadine.
The microemulsion system for fexofenadine was developed by construction of a pseudoternary phase diagram. The optimal formulation was as follows: $34.05 \%$ oil (oleic acid), $30 \%$ surfactant (span 80/lutrol F 68), 29.79\% cosurfactant (isopropyl alcohol), and 6.16\% distilled water. The optimized microemulsion was characterized according to viscosity, solubility, content of fexofenadine, conductivity, polydispersity, droplet size, and stability. In vitro and in vivo studies in Caco- 2 cells and in rabbits showed that the microemulsion had significantly improved permeability across Caco- 2 cells, a higher peak concentration and AUC, and shorter elimination half-life compared with the commercial syrup. Overall, the results indicate that the microemulsion was effective for enhancing the oral absorption of fexofenadine, and fexofenadine-loaded microemulsion demonstrates great potential for clinical application.

\section{Disclosure}

The authors report no conflicts of interest in this work.

\section{References}

1. Susman G, Mason J, Compton D, Stewart J, Ricard N. The efficacy and safety of fexofenadine $\mathrm{HCl}$ and pseudoephedrine, alone and in combination, in seasonal allergic rhinitis. J Allergy Clin Immunol. 1999;104:100-106.

2. Piao HM, Balakrishnan P, Cho HJ, et al. Preparation and evaluation of fexofenadine microemulsions for intranasal delivery. Int J Pharm. 2010;395:309-316.

3. John HK. Allergic rhinitis: current pharmacotherapy. Otolaryngol Clin North Am. 2008;41:347-358.

4. Markham A, Wagstaff AJ. Fexofenadine. Drugs. 1998;55:269-276.

5. Ujie K, Oda M, Kobayashi M, Saitoh H. Relative contribution of absorptive and secretory transporters to the intestinal absorption of fexofenadine in rats. Int J Pharm. 2008;361:7-11.

6. Garteiz DA, Hook RH, Walker BJ, Okerholm RA. Pharmacokinetics and biotransformation studies of terfenadine in man. Arzneimittelforschung. 1982;32:1185-1190.

7. Kogan A, Kesselman E, Danino D, Aserin A, Garti N. Viability and permeability across Caco-2 cells of carbamazepine solubilized in fully dilutable microemulsions. Colloids Surf B Biointerfaces. 2008;66:1-12.

8. Shimizu M, Uno T, Sugawara K, Tateishi T. Effects of itraconazole and diltiazem on the pharmacokinetics of fexofenadine, a substrate of P-glycoprotein. Br J Clin Pharmacol. 2006;61:538-544.

9. Chen C. Some pharmacokinetic aspects of the lipophilic terfenadine and zwitterionic fexofenadine in humans. Drugs R D. 2007;8:301-314.

10. Drescher S, Schaeffeler E, Hitzl M, et al. MDR1 gene polymorphisms and disposition of the P-glycoprotein substrate fexofenadine. Br J Clin Pharmacol. 2002;53:526-534. 
11. Shimizu T, Uno K, Sugawara K, Tateishi T. Effects of itraconazole and diltiazem on the pharmacokinetics of fexofenadine, a substrate of P-glycoprotein. Br J Clin Pharmacol. 2006;61:538-544.

12. Ritschel WA. Microemulsions for improved peptide absorption from the gastrointestinal tract. Methods Find Exp Clin Pharmacol. 1991;13:205-220.

13. Sarciaux JM, Acar L, Sado PA. Using microemulsion formulations for oral delivery of therapeutic peptides. Int J Pharm. 1995;120:127-136.

14. Gao Z, Choi HG, Shin HJ, et al. Physicochemical characterization and evaluation of a microemulsion system for oral delivery of cyclosporin A. Int J Pharm. 1998;161:75-86.

15. Eccleston GM. Microemulsions. In: swarbrick S, Boylan JC, editors. Encyclopedia of Pharmaceutical Technology. New York, NY: marcel Dekker; 1992.

16. Constantinides PP. Lipid microemulsions for improving drug dissolution and oral absorption: physical and biopharmaceutical aspects. Pharm Res. 1995;12:1561-1572.

17. Lin H, Gebhardt M, Bian S, et al. Enhancing effect of surfactants on fexofenadine- $\mathrm{HCl}$ transport across the human nasal epithelial cell monolayer. Int J Pharm. 2007;330:23-31.

18. Jadhav KR, Shaikh IM, Ambade KW, Kadam VJ. Applications of microemulsion based drug delivery system. Curr Drug Deliv. 2006;3:267-273.

19. Yin YM, Cui FD, Mu CF, et al. Docetaxel microemulsion for enhanced oral bioavailability: preparation and in vitro and in vivo evaluation. J Control Release. 2009;140:86-94.

20. Karakuş S, Küçükgüzel I, Küçükgüzel GS. Development and validation of a rapid RP-HPLC method for the determination of cetirizine or fexofenadine with pseudoephedrine in binary pharmaceutical dosage forms. J Pharm Biomed Anal. 2008;46:295-302.

21. Ghosh PK, Majithiya RJ, Umrethia ML, Murthy RS. Design and development of microemulsion drug delivery system of acyclovir for improvement of oral bioavailability. AAPS Pharm Sci Tech. 2006; $7: 77$.

22. Cui J, Yu B, Zhao Y, et al. Enhancement of oral absorption of curcumin by self-microemulsifying drug delivery systems. Int J Pharm. 2009;371:148-155.
23. Gonzalez-Alvarez I, Gonzalez-Alvarez M, Oltra-Noguera D, et al. Unique pharmacology of KAR-2, a potential anti-cancer agent: absorption modeling and selective mitotic spindle targeting. Eur J Pharm Sci. 2008;36:9-11

24. Golightly LK, Greos LS. Second-generation antihistamines: actions and efficacy in the management of allergic disorders. Drugs. 2005;65:341-384

25. Peng SX, Ritchie DM, Cousineau M, Danser E, Dewire R, Floden J. Altered oral bioavailability and pharmacokinetics of P-glycoprotein substrates by coadministration of biochanin A. J Pharm Sci. 2006;95: 1984-1993.

26. Ogasawara A, Kume T, Kazama E. Effect of oral ketoconazole on intestinal first-pass effect of midazolam and fexofenadine in cynomolgus monkeys. Drug Metab Dispos. 2007;35:410-418.

27. Li Y, Zhang M, Wang J, Zhang S, Liu J, Zhang Q. Effects of absorption enhancers on intestinal absorption of lumbrokinase. Yaо Хие Хие Ваo. 2006;41:939-944. Chinese.

28. Yamamoto A, Uchiyama T, Nishikawa R, Fujita T, Muranishi S. Effectiveness and toxicity screening of various absorption enhancers in the rat small intestine: effects of absorption enhancers on the intestinal absorption of phenol red and the release of protein and phospholipids from the intestinal membrane. J Pharm Pharmacol. 1996;48:1285-1289.

29. Alany RG, Rades T, Agatonovic-Kustrin S, Davies NM, Tucker IG. Effects of alcohols and diols on the phase behaviour of quaternary systems. Int J Pharm. 2000;196:141-145.

30. Podlogar F, Gasperlin M, Tomsic M, Jamnik A, Rogac MB. Structural characterisation of water-Tween 40/Imwitor 308-isopropyl myristate microemulsions using different experimental methods. Int J Pharm. 2004;276:115-128.

31. Langguth P, Bohner V, Heizmann J, et al. The challenge of proteolytic enzymes in intestinal peptide delivery. $J$ Control Release. 1997;46:39-57.

32. Lappin G, Shishikura Y, Jochemsen R, et al. Pharmacokinetics of fexofenadine: evaluation of a microdose and assessment of absolute oral bioavailability. Eur J Pharm Sci. 2010;40:125-131.

33. Kumar L, Alam MS, Meena CL, Jain R, Bansal AK. Fexofenadine hydrochloride. Profiles of Drug Substances, Excipients and Related Methodology. 2009;34:153-192.
International Journal of Nanomedicine

\section{Publish your work in this journal}

The International Journal of Nanomedicine is an international, peerreviewed journal focusing on the application of nanotechnology in diagnostics, therapeutics, and drug delivery systems throughout the biomedical field. This journal is indexed on PubMed Central, MedLine, CAS, SciSearch ${ }^{\circledR}$, Current Contents ${ }^{\circledR} /$ Clinical Medicine,

\section{Dovepress}

Journal Citation Reports/Science Edition, EMBase, Scopus and the Elsevier Bibliographic databases. The manuscript management system is completely online and includes a very quick and fair peer-review system, which is all easy to use. Visit http://www.dovepress.com/ testimonials.php to read real quotes from published authors. 